\title{
Evidence for a Third Taxonomic Subgroup of Peanut Stunt Virus from China
}

\author{
Xu Zeyong, Oil Crops Research Institute, Chinese Academy of Agricultural Sciences, 430062 Wuhan, China; Col- \\ leen M. Higgins, QDPI Queensland Agricultural Biotechnology Centre, The University of Queensland, Qld 4072, \\ Brisbane, Australia; Chen Kunrong, Oil Crops Research Institute, Chinese Academy of Agricultural Sciences, \\ 430062 Wuhan, China; Ralf G. Dietzgen, QDPI Queensland Agricultural Biotechnology Centre, The University of \\ Queensland, Qld 4072, Brisbane, Australia; and Zhang Zhongyi, Yang Liying, and Fang Xiaoping, Oil Crops Re- \\ search Institute, Chinese Academy of Agricultural Sciences, 430062 Wuhan, China
}

\begin{abstract}
Zeyong, X., Higgins, C. M., Kunrong, C., Dietzgen, R. G., Zhongyi, Z., Liying, Y., and Xiaoping, F. 1998. Evidence for a third taxonomic subgroup of peanut stunt virus from China. Plant Dis. 82:992-998.

On the basis of host reactions and serology, six Chinese peanut stunt virus (PSV) strains were found to be distinct from PSV-E and PSV-W, two type strains representing distinct serological subgroups. Chinese PSV strains were characterized by infecting Chenopodium amaranticolor and $C$. quinoa systemically. All Chinese strains were serologically closely related to each other, but distinct from PSV-E and more distant from PSV-W. Using two PSV-specific primers designed from conserved regions of the PSV RNA3 nucleotide sequence, cDNA transcribed from RNA3 of two Chinese PSV strains, Mi and S, was amplified by PCR and cloned. The sequenced cDNA of the two PSV strains included 654 nt of the coat protein (CP) gene. The identity of the CP gene nucleotide sequence between PSV-Mi and PSV-S was 99.0\%, with $99.5 \%$ amino acid identity. Identity of the CP gene nucleotide sequence was 75.6 to $77.8 \%$ between PSV-Mi and -S (the two Chinese strains) and PSV-ER and -J in PSV subgroup I; and 74.1 to $74.4 \%$ between PSV-Mi and -S, and PSV-W in subgroup II. Based on these results, we propose placing PSV Chinese strains into a new PSV subgroup III.
\end{abstract}

Additional keywords: coat protein gene, cucumovirus

Peanut stunt virus (PSV) is economically important in China. It has caused severe epidemics in the major peanut growing provinces in northern China since the early 1970s (25). A PSV strain isolated from an infected peanut plant was first identified and designated as mild strain, PSV-Mi, in 1985 (24). Subsequently, a PSV isolate causing mosaic in black locust was reported in 1990 (26). Disease surveys revealed that black locust trees (Robinia pseudoacacia L.), a popular tree in northern China, are widely infected by PSV and could act as a primary source of the virus for peanut (Arachis hypogaea L.) and other susceptible plants (23). PSV was also found naturally infecting bean (Phaseolus vulgaris L.) and a legume shrub (Falso indigo L.) in China.

PSV is a member of the genus $\mathrm{Cucu}$ movirus in the family Bromoviridae (19)

Corresponding author: Xu Zeyong; Fax: 8627 6816451; E-mail: ocgil@public.wh.hb.cn

The partial sequences of RNA3 of PSV-Mi and PSV-S have been deposited in the EMBL database with accession numbers AJ222804 and AJ222803, respectively.

Accepted for publication 26 May 1998.

Publication no. D-1998-0713-01R

(C) 1998 The American Phytopathological Society and has been reported to infect peanut, black locust, bean, soybean (Glycine $\max$ (L.) Merr.), pea (Pisum sativum L.), tobacco (Nicotiana tabacum L.), celery (Apium graveolens L.), and many forage legumes (22). Since a western strain (PSVW) was reported in 1969 as a new serotype of PSV different from PSV-E, other isolates or strains, namely PSV-J, PSV-V, PSV-H, PSV-B, PSV-T, PSV-Tp, and PSV$\mathrm{C}$, have been reported worldwide based on host reactions and serology $(2,14,15,22)$. On the basis of serological relationship and nucleic acid competition hybridization, PSV strains have been divided into two major groups, eastern and western $(4,22)$. Naidu et al. (17) confirmed the existence of this grouping based on the ability of PSV strains to support the replication of satRNA and on homologies detected by Northern blot analysis. Hu et al. (8) classified PSV strains into two distinct subgroups: I, for PSV-E and related strains, and II, for PSV-W, based on nucleotide sequence identity of RNA3 open reading frames (ORFs) and untranslated regions (UTRs).

Little is known about PSV strain differences in China and about relationships between Chinese PSV strains and those from other parts of the world. Information on the variability of the virus can assist in determining criteria to identify and select peanut cultivars for PSV resistance and to better understand the evolution and ecology of PSV (12). We collected six PSV isolates from diverse sources in China and compared them with the strains from the United States to determine their relationships by indicator host reactions, serology, and coat protein gene sequence analysis.

\section{MATERIALS AND METHODS}

Host reactions. Seven PSV isolates were maintained in peanut plants. PSV-Mi, PSV-13, and PSV-S were isolated from infected peanut plants in Zenzhou, Henan Province, Taian, Shandong Province, and Beijing, respectively. PSV-R, PSV-F, and PSV-P were isolated from black locust, $F$. indigo, and bean, respectively, in Beijing, and PSV-E was provided by T. T. Hebert, North Carolina State University, Raleigh.

Host reactions of the PSV isolates were compared on 19 plant species under greenhouse conditions. Six to 10 plants of each species were sap-inoculated with infected tissue ground in $0.05 \mathrm{M}$ potassium phosphate buffer, $\mathrm{pH}$ 7.0, containing 0.01 M 2mercaptoethanol. Symptomless plants were tested by enzyme-linked immunosorbent assay (ELISA) to determine if plants were infected.

Tests for the effect of PSV strains on growth and yield of peanut were carried out in an aphid-proof chamber using peanut cultivar Baisha 1016. Plants were grown in a space $10 \times 33 \mathrm{~cm}$; 60 plants in four rows were inoculated with each of the seven PSV strains at the first leaf stage. Another 30 uninoculated plants served as controls. Symptoms were observed, and the effect of each PSV strain on growth and yield of peanut was measured.

Purification and serology. PSV isolates were propagated on Nicotiana hybrida. The purification procedure was a modification of that reported by Francki et al. (7) for cucumber mosaic virus (CMV). For antiserum preparation, the rabbits received subcutaneous injections at 2-week intervals. Serum collection began after the fifth injection. The serological relationships of PSV strains were determined by gel double diffusion tests, which were conducted in $1 \%$ agarose gel in $0.03 \mathrm{M}$ phosphate buffer, $\mathrm{pH} 7.0$, containing $0.1 \% \quad \mathrm{NaN}_{3}$. Besides the above seven PSV strains, PSVW from G. I. Mink, Washington State University, Prosser, was also included in the 
analysis. Extracts of young, infected peanut leaves were used as antigens.

Cloning and sequencing of the $\mathrm{CP}$ gene cDNA of PSV-Mi and PSV-S. Two primers were designed from conserved nucleotide sequences in RNA3 of PSV strains J and ER (GenBank database accession numbers D00668 and U15730, respectively) and synthesized by the Centre for Molecular and Cellular Biology, The University of Queensland. The upstream primer PSV 2 (5'-CGATATACCTTTTGGGTTCA-3') corresponded to nucleotides 1,100 to 1,119 of PSV-J RNA3 (9). The downstream primer PSV 1 (5'-TCACAATCACCAGGAGTAGA-3') corresponded to bases 2,119 to 2,100 within the
3' untranslated region of PSV-J RNA3 (9) and is also conserved in RNA 1 and 2 (10).

Reverse transcription-polymerase chain reaction (RT-PCR) using purified PSV RNA or virus was carried out using an Access RT-PCR kit from Promega (Madison, WI) according to their instructions. Two microliters of PSV RNA (20 to $25 \mathrm{ng} / \mu \mathrm{l})$ was used as template, to which $50 \mu \mathrm{M}$ each of PSV 1 and PSV 2 primers was added. RT-PCR amplification was carried out in a Perkin Elmer DNA Thermal Cycler 480 (Norwalk, CT) using the following program: cDNA synthesis at $48^{\circ} \mathrm{C}$ for $60 \mathrm{~min}$ followed by denaturation at $94^{\circ} \mathrm{C}$ for $2 \mathrm{~min}, 40$ cycles of PCR $\left(94^{\circ} \mathrm{C}\right.$, $\left.30 \mathrm{~s} ; 50^{\circ} \mathrm{C}, 1 \mathrm{~min} ; 68^{\circ} \mathrm{C}, 2 \mathrm{~min}\right)$, and $7 \mathrm{~min}$ final extension at $68^{\circ} \mathrm{C}$.

Amplified DNA was analyzed by electrophoresis through a $1 \%$ agarose/TBE gel. A band of $1 \mathrm{~kb}$ was purified using a QIAquick gel extraction kit from Qiagen (Hilden, Germany) and ligated to the TA cloning vector pCR from Invitrogen (San Diego, CA). Chemically competent Escherichia coli cells were transformed with plasmid DNA as described by Messing (13). Plasmid DNA was prepared by alkaline lysis for sequencing according to the recommendations of Applied Biosystems Inc. (Norwalk, CT). Double-stranded DNA was sequenced by the dideoxy-nucleotide chain termination method (20) using an

Mi CGAUAUACCU UUUGgGUUCA AUUCCCUUUG GUCAAUUUUG CGUUCCUUUA AUUCCAGGAU ACUUACCCUG 70 $\mathrm{S}$

Mi AAGUUCUUGU AGUAUCAUCG CAUUCGUUUG UAUUGUGUUU ACUAUUCUAC GCGUCAACCA CAAGUUAAAU 140

Mi GGCAUCUUCA GGAUCUGGUA GCGGUUCUCG UCGACCCCGC AGGGGAAGAC GCAAUUCAUC UGCUAAAGUG 210

$\mathrm{S}$

Mi GACGCUCACG CUAGAGAGCU CCGCGCCCUG ACUGCUCAGG UGAACCGUUU GGUAGCCAUC ACAGCUGCCC 280

$S$ -

Mi AAGUGCCAUC CCUCGAUCAU CCAACCUUUG UUUCUAGCAA GAAGUGUCGU CCUGGGUACA CGUACACUUC 350

$\mathrm{s}$

Mi GUUGGAUGUU AAGCCGGCUA AAACUGAGAA GGGUCAAAGU UUCGGCAAGA GGUUAUCCUU ACCAGCUCCC 420

$S$ -

Mi GUAUCCGAAU UUCCGAAGAA GAAGAUUUCG UGUAUUCAGC UUAGGCUGAA UCCGUCGCCU AAGUUCGAUU 490

$\mathrm{s}$

Mi CCACCAUCUG GGUAUCUCUU AGGCGUUUGC CCAAAGACUA CUCUCUUGCU UCGGAAAGCG UGUUUAAGCU 560

S - -

Mi CUUCACAGAU GgUAAUGCAG CAGUGCUUAU CUAUCAACAC GUCUCGACCG GUAUUCAACC CCGUAACAAA 630

$\mathrm{S}$

Mi AUCACCUUCG AUUUGGCUUC UGUUGGAGCG GAGAUAGGUG AUCUCGGCGA AUAUGCCGUG AUCGUCUAUU 700

$\mathrm{S}$

Mi CCAAGGACGA CGUUCUAGAA GCUGACGAGG UGGUGAUACA CGUAGAUGUG GAGCACCAGC GAAUCCCUUC 770

$\mathrm{S}$

Mi CGCCACAGCU CUCCCGGUCU AGAGUUCGGG UACAAGUCCG AAGACGAUAA ACUACACUCU CUCUCUUGCG 840

S

Mi AGUGCUAAGU UGGCAGCUAU AUUACUCUAA ACUGCCUGAA GUCGCUAAAU AGGGUUUCCU AGCGAUCGGG 910

S

Mi UUGUCCAUCC AGCUAACGGC UAAAAUGGUC AGUCUUACCU UUCGGUAAGC CAGGUUCUUA CAAGGAUCUG 980

S

Mi agguacuUUa uaucaucuac uCCuggugau uguga

1050

S

Fig. 1. Partial nucleotide sequence of RNA3 of peanut stunt virus (PSV)-Mi and -S. The differences between the nucleotide sequences of PSV-Mi RNA3 and PSV-S RNA3 are indicated; dashed lines indicate an identical nucleotide. The open reading frame of the coat protein gene is underlined. 
ABIPRISM Dye terminator Cycle Sequencing Reddy Reaction kit supplied by Perkin Elmer. The oligonucleotide primers used for sequencing included the original RT-PCR primers PSV 1 and PSV 2, and internal sequencing primers PSV 3 (5'GTGGCGGAAGGGATTCGCTGG-3') and PSV 4 (5'-GACTGCTCAGGTAGGCCGTTTG-3'), and the universal forward and reverse primers. Primers PSV 3 and PSV 4 corresponded to nucleotides 776 to 756 and 240 to 261, respectively, of the PSV-Mi partial RNA3 sequence (Fig. 1). Three independent RT-PCR clones of each of PSV-S and PSV-Mi were sequenced.

Computer analysis of DNA sequences. The PSV-S and PSV-Mi sequences were compared at the nucleotide and amino acid levels with the corresponding sequences from PSV, tomato aspermy virus (TAV), and CMV isolates found on the GenBank database. The PSV sequences analyzed were PSV-ER (U15730) (17), PSV-J (D00668) (9), and PSV-W (U31366) (8). Three TAV sequences were included in the comparisons, of which two are shown in Table 1, i.e., TAV-C (D01015) and TAV-P (L15335). The third TAV sequence was TAV-British (S72648). CMV subgroup I sequences represented in Table 1 were CMV-Y (M57602) and CMV-Fny (D10538), while the subgroup II sequences represented were CMV-Q (M21464) and CMVtrk7 (L15336). Additional CMV subgroup I sequences included in the pairwise comparisons and phylogenetic tree (Fig. 2) were two additional Y strains (M22710, D83959), Kor (L36251), M (D10539), Ny (U22821), O (D00385), AS (X77855), and NT9 (D28780). Additional CMV subgroup II sequences were Kin (Z12818), WL (D00463), and Sn (U22822).

All nucleotide and predicted amino acid sequences of the PSV strains were assembled using programs networked by the Australian National Genomic Information Service (ANGIS). These programs included the GCG version 8.1.0 programs of the Wisconsin Computer Group Inc. Sequences were compiled using the sequence editing program SIMSEQED and translated to obtain the predicted amino acid

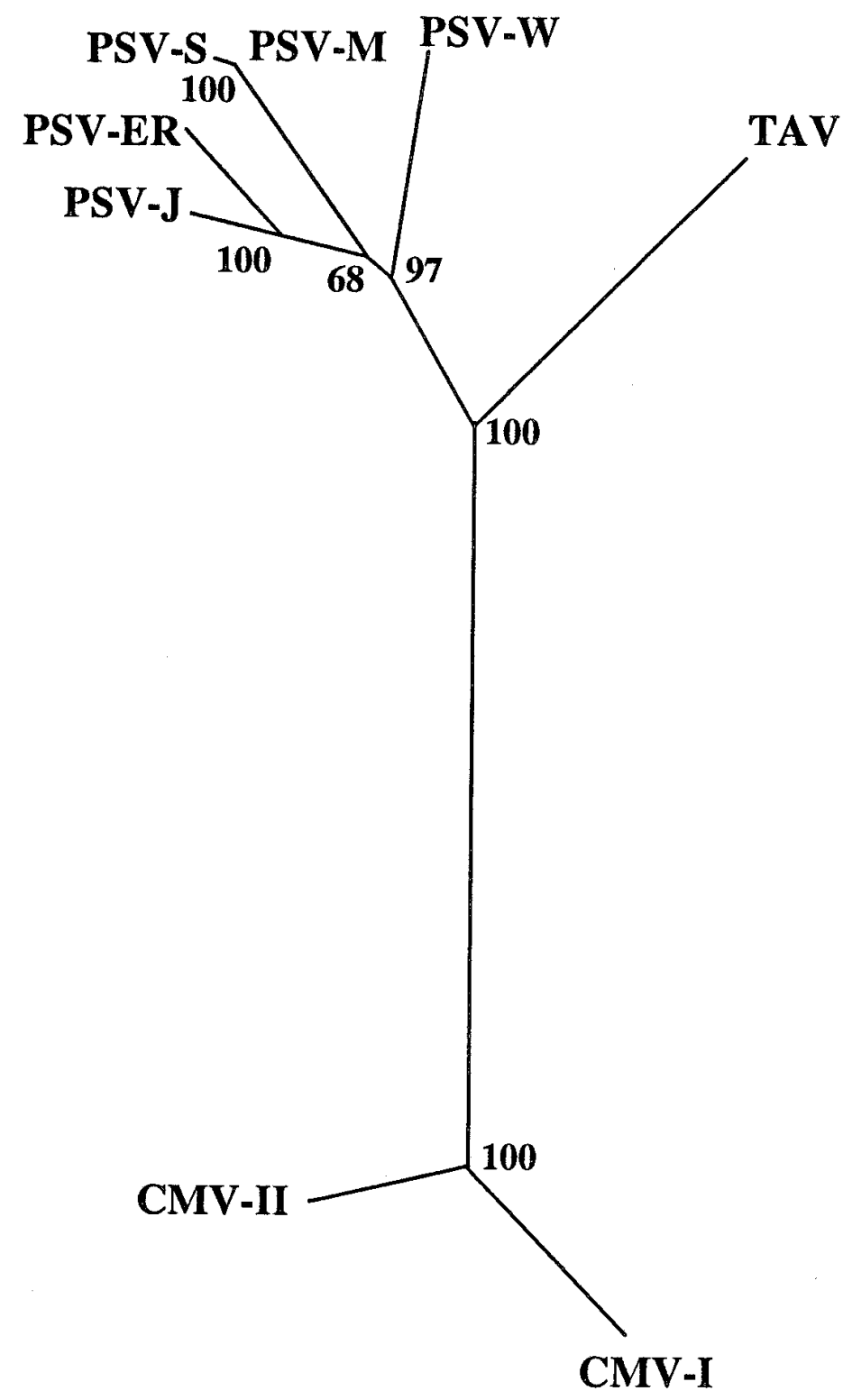

Fig. 2. Neighbor joining tree showing the phylogenetic relationship of the Chinese peanut stunt virus (PSV) coat protein nucleotide sequences to those of other PSV strains and to tomato aspermy virus (TAV) and cucumber mosaic virus (CMV) subgroups I and II. The location on the tree of the CMV and TAV sequences included in this study are shown as branches leading to the TAV clade and the clades of the recognized subgroups of CMV. The relevant bootstrap values are shown at the nodes.

Table 1. Percent identity of coat protein gene nucleotide and deduced amino acid sequences among peanut stunt virus (PSV)-Mi and -S, and other strains of PSV, cucumber mosaic virus (CMV), and tomato aspermy virus (TAV) ${ }^{\mathrm{a}}$

\begin{tabular}{|c|c|c|c|c|c|c|c|c|c|c|c|}
\hline & \multicolumn{5}{|c|}{ PSV } & \multicolumn{4}{|c|}{ CMV } & \multicolumn{2}{|c|}{ TAV } \\
\hline & Mi & $\mathbf{S}$ & ER & $\mathbf{J}$ & $\mathbf{W}$ & Fny & $\mathbf{Y}$ & $\mathbf{Q}$ & Trk7 & $\mathbf{P}$ & $\mathbf{C}$ \\
\hline PSV Mi & & 99.0 & 75.6 & 77.8 & 74.4 & 54.3 & 51.5 & 55.1 & 54.6 & 67.6 & 67.7 \\
\hline $\mathrm{S}$ & 99.5 & & 75.6 & 77.5 & 74.1 & 53.0 & 52.2 & 54.5 & 54.0 & 67.4 & 67.5 \\
\hline ER & 83.6 & 83.7 & & 86.8 & 75.0 & 55.5 & 54.8 & 52.6 & 53.1 & 66.6 & 66.4 \\
\hline $\mathrm{J}$ & 86.2 & 86.2 & 90.2 & & 77.5 & 56.0 & 55.3 & 55.9 & 55.5 & 67.0 & 66.8 \\
\hline W & 79.5 & 79.5 & 79.1 & 80.9 & & 53.3 & 52.6 & 55.7 & 54.7 & 61.9 & 62.0 \\
\hline CMV Fny & 67.9 & 67.4 & 65.3 & 69.8 & 63.3 & & 97.7 & 75.3 & 74.3 & 52.8 & 52.9 \\
\hline $\mathrm{Y}$ & 67.4 & 67.0 & 64.8 & 66.5 & 62.8 & 98.2 & & 75.6 & 74.6 & 52.8 & 52.9 \\
\hline Q & 69.1 & 68.7 & 66.2 & 68.7 & 63.7 & 91.3 & 89.9 & & 98.6 & 54.0 & 54.4 \\
\hline Trk7 & 68.2 & 67.7 & 65.7 & 68.2 & 63.7 & 89.9 & 88.5 & 98.2 & & 53.6 & 54.0 \\
\hline TAV P & 81.2 & 81.2 & 78.5 & 78.4 & 73.0 & 67.9 & 66.2 & 65.3 & 64.8 & & 99.8 \\
\hline $\mathrm{C}$ & 78.9 & 78.9 & 78.2 & 76.1 & 70.7 & 65.6 & 63.9 & 65.3 & 64.8 & 96.8 & \\
\hline
\end{tabular}

${ }^{a}$ Coat protein gene nucleotide sequence identity above diagonal, amino acid sequence similarity below diagonal. 
sequences using GCG TRANSLATE. Pairwise sequence comparisons were done using GCG-GAP.

Multiple alignments of the nucleotide and protein sequences were obtained using CLUSTALW (21), while phylogenetic analyses of these alignments were done using version 3.5 of the PHYLIP package (6). Distance matrices were calculated from the sequence alignments using the Kimura 2-parameter matrix (11) in the program DNADIST for the nucleotide sequences and using the Dayhoff PAM matrix (3) in the program PROTDIST for protein sequences. Phylogenies were inferred from these distance matrices using the NEIGHBOUR JOINING method, and the phylogenetic trees were visualized using the DRAWTREE program in PHYLIP. The statistical significance of the branching order was estimated using SEQBOOT (5) from 100 resamplings of the original alignment, and from these a consensus tree with branch lengths proportional to distance was built using CONSENSE.

\section{RESULTS}

Host reactions. Of 19 species tested, 11 were selected as indicator plants for distinguishing PSV strains. Their reactions to seven PSV strains are shown in Table 2. Virus strains could be divided into three groups based on their host range and symptomatology.

Groups A and B comprised all six Chinese PSV isolates, which clearly differed from PSV-E (group C) based on the reactions of six of the 11 host plants. All six Chinese PSV strains induced both local lesions and systemic mosaic on Chenopodium amaranticolor and $C$. quinoa, whereas PSV-E only caused local lesions on inoculated leaves of both species without systemic infection. Chinese PSV strains also infected black locust locally or systemically. PSV-E did not infect black locust. On the other hand, PSV-E produced systemic mosaic on Trifolium pratense, Petunia florida, and Zinnia elegans. Chinese PSV strains did not infect the three species, except PSV-P, which caused local lesions on the inoculated leaves of $Z$. elegans.

On the basis of severity of symptoms induced on peanut, cowpea (Vigna sinensis), bean, pea, and N. hybrida, the seven PSV strains could be divided into virulent and less virulent strains. PSV-S, PSV-13, PSV$\mathrm{P}$, and PSV-E in groups $\mathrm{B}$ and $\mathrm{C}$ were virulent and incited severe symptoms on infected peanut plants, including small and deformed leaves and severe stunting. Those PSV strains also caused necrotic wilting on pea, numerous local chlorotic and ring spots and severe mosaic on bean and cowpea, and severe mosaic on N. hybrida. In contrast, PSV-Mi, PSV-R, and PSV-F in group A were less virulent, causing only mild mosaic on leaves and slight stunting of infected peanut plants. They produced fewer local lesions and mild mosaic on leaves of bean and cowpea, and mild mosaic on $N$. hybrida, but did not infect pea.

All seven PSV isolates produced the same or similar reactions on the other eight plant species tested (data not shown). They infected soybean and Sesbania cannabina systemically and Phaseolus mungo and sesame (Sesamum indicum) locally. Most of the PSV strains infected Cassia occidentalis and Datura stramonium systemically. However, they did not infect tomato (Lycopersicon esculentum) and pepper (Capsicum annuum).

The effect of PSV strains on growth and yield of peanut plants varied between virulent and less virulent strains. Early infection by the virulent strains, PSV-S, PSV-13, PSV-E, and PSV-P, reduced the height of the main stems by 17 to $47 \%$ compared with 3.5 to $16 \%$ height reduction from infection by the three less virulent PSV strains, PSV-Mi, PSV-R, and PSV-F. The virulent strains also decreased peanut pod yield by 58 to $86 \%$ compared with 41 to $47 \%$ yield reduction by the less virulent PSV strains.

Serological relationships. Yields of purified virus varied greatly among the six strains purified from $100 \mathrm{~g}$ of $N$. hybrida leaves: $40 \mathrm{mg}$ of PSV-S, $29 \mathrm{mg}$ of PSV-13, $25.2 \mathrm{mg}$ of PSV-P, $12.4 \mathrm{mg}$ of PSV-Mi, 6.5 $\mathrm{mg}$ of PSV-R, and $0.8 \mathrm{mg}$ of PSV-E. Titers of antisera produced to PSV-S, PSV-P, PSV-Mi, and PSV-R were 1:256 by gel diffusion tests (data not shown).

Sap from young infected peanut leaf consistently gave sharp precipitin lines in gel diffusion tests (Fig. 3). Two precipitin bands were formed with some virus-serum combinations: a straight band near the central well and a curved band near the antigen. The curved band was used to distinguish serological relationships by the presence or absence of spurs between bands from adjacent antigens. PSV-E consistently gave apparent spurs over precipitin lines of all six Chinese PSV strains when diffused against antiserum to PSV-E. In the reverse, PSV-Mi, PSV-R and S, and PSV-P produced apparent spurs over PSVE precipitin lines in tests with PSV-Mi, -R, and $-\mathrm{P}$ antisera, respectively, which indicated that PSV-E is distinguishable from the Chinese strains. Furthermore, PSV-W gave no precipitin band formation, indicating that this strain was more distant serologically from the Chinese strains. In contrast, the precipitin lines between the Chinese strains either were confluent or formed a weak spur in tests with all five antisera, which demonstrated a close serological relationship among Chinese PSV strains.

Nucleotide sequence analysis of the CP gene of PSV-Mi and PSV-S. With purified virus or RNA of PSV-Mi and $-\mathrm{S}$ as templates, an expected 1,015-bp product was amplified by RT-PCR from both PSV strains (data not shown). These DNA fragments derived from RNA3 were cloned and sequenced.

The partial nucleotide sequences of RNA3 of PSV-Mi and $-\mathrm{S}$ are shown in Figure 1, with numbering beginning with the 5'-terminal nucleotide. The sequence contained an ORF of $654 \mathrm{bp}$ (including the stop codon) for the coat protein, $138 \mathrm{bp}$ of a $5^{\prime}$ noncoding sequence, and 223 bp of $3^{\prime}$ untranslated sequence. The ORF can encode a protein of 217 amino acids, which is

Table 2. Reactions of herbaceous plant species to seven strains of peanut stunt virus

\begin{tabular}{|c|c|c|c|c|c|c|c|}
\hline \multirow[b]{2}{*}{ Species } & \multicolumn{3}{|c|}{ Group A strains } & \multicolumn{3}{|c|}{ Group B strains } & \multirow{2}{*}{$\begin{array}{c}\text { Group C strain } \\
\text { PSV-E }\end{array}$} \\
\hline & PSV-F & PSV-R & PSV-Mi & PSV-13 & PSV-S & PSV-P & \\
\hline Chenopodium amaranticolor & $\mathrm{LLc} / \mathrm{Mo}^{\mathrm{a}}$ & LLc/Mo & LLc/Mo & LLC/Mo & LLc/Mo & LLc/Mo & LLc/- \\
\hline C. quinoa & LLc/Mo & LLc/Mo & LLc/Mo & LLC/Mo & LLc/Mo & LLc/Mo & LLc/- \\
\hline Trifolium pratense & $-1-$ & $-1-$ & $-1-$ & $-1-$ & $-1-$ & $-1-$ & $-/ \mathrm{Mo}$ \\
\hline Petunia hybrida & $-1-$ & $-1-$ & $-1-$ & $-1-$ & $-1-$ & $-1-$ & $-/ \mathrm{Mo}$ \\
\hline Zinnia elegans & $-1-$ & $-1-$ & $-1-$ & $-1-$ & $-1-$ & LLc/- & $-/ \mathrm{Mo}$ \\
\hline Robinia pseudoacacia & LLn/- & LLn/Mo & LLn/- & LLy/- & LLc/Mo & LLy/Mo & $-1-$ \\
\hline Arachis hypogaea & -/CMo & -/CMo & -/CMo & -/CMo.Stu & -/CMo.Stu & -/CMo.Stu & LLc/Mo.Stu \\
\hline Pisum sativum & $-1-$ & $-1-$ & $-1-$ & $\mathrm{LLc} / \mathrm{La}$ & LLn/SN & LLc/SN & $\mathrm{LLn} / \mathrm{SN}$ \\
\hline P. vulgaris & -/SMo & -/SMo & LLc1/Mo & LLc2/Mo & LLc3/Mo & LLc3/Mo & LLc3/Mo \\
\hline Vigna sinensis & -/SMo & LLc2/Mo & LLc1/SMo & LLc2/Mo & LLc3/Mo & LLc2/Mo & LLc2/Mo \\
\hline Nicotiana hybrida & -/SMo & -/SMo & -/SMo & $-/ \mathrm{Mo}$ & $-/ \mathrm{Mo}$ & $-/ \mathrm{Mo}$ & $-/ \mathrm{Mo}$ \\
\hline
\end{tabular}

a Inoculated leaves/uninoculated leaves. 1 = few, $2=$ several, $3=$ many local lesions; $-=$ no infection, LLc = local chlorotic lesions, LLn = local necrotic lesions, LLy = local yellow spots, Mo = mosaic, CMo = common mosaic, SMo = slight mosaic, $\mathrm{SN}=$ systemic necrosis, $\mathrm{Stu}=$ stunt, La = latent infection. 
comparable to that reported for the coat protein gene of other PSV strains $(9,16)$.

Sequence comparisons of the coat protein gene showed that the two Chinese PSV strains, S and Mi, were $99.0 \%$ identi$\mathrm{cal}$ at the nucleotide level and $99.5 \%$ identical at the amino acid level (Table 1). This latter value corresponded to one amino acid change over the 217 amino acid length of the coat protein. The amino acid difference is at position 77, where an alanine (Mi) is replaced by a valine. This high level of amino acid sequence identity between these two strains explained their close serological relationship. The degree of identity between these two strains was much higher than that observed between the $\mathrm{CP}$ of strains ER and $\mathrm{J}$, which have been classified as members of the same subgroup (8). PSV-ER and -J were found to be only $86.8 \%$ identical at the nucleotide level (Table 1). The Chinese strains were more distantly related to the western subgroup (PSV-W) than to the eastern subgroup (PSV-ER, PSV-J) and were closer to PSV-J than to PSV-ER (Table 1).

The close relationship between the Chinese strains compared with the others was further supported by the phylogenetic analysis. The neighbor joining tree in Figure 2 showed clearly that the Chinese strains had a closer relationship than the PSV-ER and -J strains. Further, it would appear from this tree that PSV-Mi may have been a progenitor of PSV-S, while the PSV-ER and - $\mathrm{J}$ strains have diverged from a common ancestor. All of the PSV strains studied here appear to have had a common ancestor, with PSV-W diverging earlier than the others.

The PSV strains showed much greater sequence variation than the other virus species of Cucumovirus (Table 1). The variation among the PSV strains was 1.0 to $25.9 \%$ and 0.5 to $20.9 \%$ at the nucleotide and deduced amino acid levels, respectively. This is compared to 0 to $0.2 \%$ and 0 to $3.2 \%$ for TAV, and 0 to $7.3 \%$ and 0 to $5.0 \%$ for CMV.

PSV was more closely related to TAV than to CMV. The variation between PSV and TAV was 32.8 to $38.2 \%$ and 18.8 to $29.3 \%$ at the nucleotide and amino acid levels, respectively, compared to 43.6 to
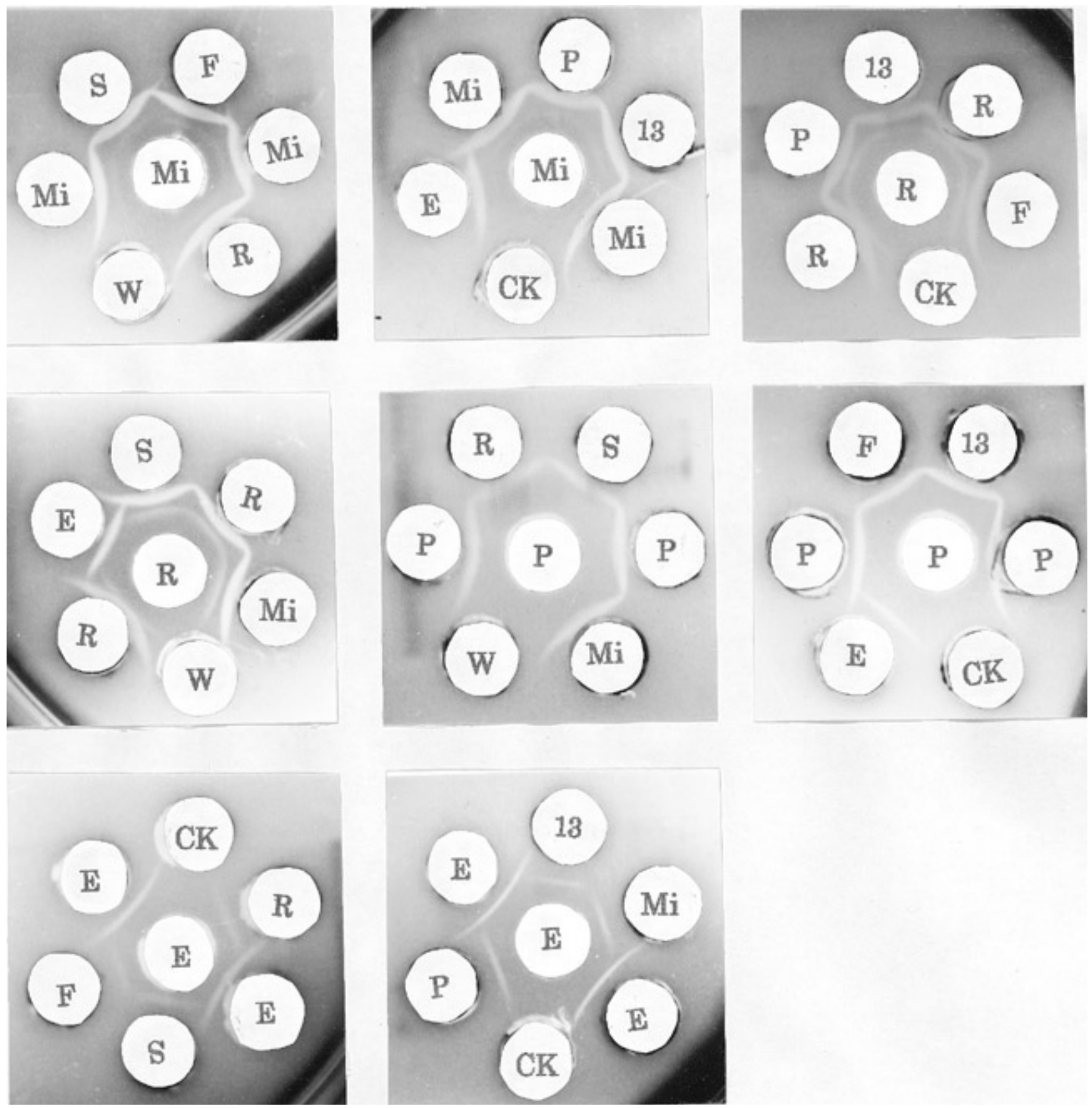

Fig. 3. Serological reactions of eight peanut stunt virus (PSV) strains with antisera (center wells) to PSV-Mi, PSV-R, PSV-P, and PSV-E in gel double diffusion tests. The outer wells were filled with extracts of young peanut leaves infected by PSV strains as antigens. Antigens: Mi = PSV-Mi, S = PSV-S, R $=\mathrm{PSV}-\mathrm{R}, \mathrm{F}=\mathrm{PSV}-\mathrm{F}, \mathrm{P}=\mathrm{PSV}-\mathrm{P}, 13$ = PSV-13, $\mathrm{E}=\mathrm{PSV}-\mathrm{E}, \mathrm{W}=\mathrm{PSV}-\mathrm{W}, \mathrm{CK}=$ healthy peanut leaves. 
$50.3 \%$ and 30.2 to $39.1 \%$ between PSV and CMV nucleotide and amino acid sequences, respectively. The close relationship between PSV and TAV is further illustrated in Figure 2. The distance between PSV and TAV on the phylogenetic tree was much less than that observed between PSV and both subgroups of CMV.

\section{DISCUSSION}

On the basis of host reactions and serology, all six Chinese PSV strains were distinct from subgroup I (E, ER, J) and subgroup II (W) strains, which have been well-defined by serological and molecular means (8). Chinese PSV strains infected $C$. amaranticolor and $C$. quinoa systemically, while PSV-E (this study) and PSV-W (15) infected these species only locally. Of the many PSV strains or isolates from diverse source plants worldwide, all but one from Sudan were also reported to infect $C$. amaranticolor locally, including PSV-Tp, PSVB, PSV-T, PSV-J, PSV-I, and many other PSV isolates from the United States $(1,2,14)$. However, reactions on $C$. quinoa were reported to vary among the PSV strains. Chinese PSV strains were also distinguishable by not infecting Trifolium pratense, Petunia hybrida, and Zinnia elegans, and by infecting black locust. Further, virulence among Chinese PSV strains could be distinguished based on their reactions on peanut, cowpea, bean, and $N$. hybrida. This corresponds to the variation in the severity of PSV disease from mild mosaic to severe mosaic and stunting of infected plants observed in the peanut fields in various areas $(\mathrm{Z} . \mathrm{Xu}, \mathrm{Z}$. Zhang, and K. Chen, unpublished).

Serologically, PSV strains were reported to vary significantly. Mink et al. (15) first reported PSV-W as a new serotype of PSV that differed from the eastern strain (PSVE). Beczner and Devergne (2) reported PSV-Tp as a new strain serologically distinct from serotypes PSV-V (equivalent to PSV-E) and PSV-W. Subsequently, Xu et al (22) divided 13 PSV isolates from the United States into two serogroups based on relatedness to PSV-E and PSV-W. The PSV-E group comprised three distinct serotypes. Based on reactions in our gel double diffusion tests, all six Chinese PSV strains showed close serological relationships to each other and could be considered a new serogroup.

Based on previous nucleotide sequence comparisons, classification of PSV into two subgroups that correspond to the two serogroups has been made $(8,17)$. From our study of Chinese strains, we propose that the PSV strains be divided into three subgroups and suggest that, due to the high level of sequence variation of this virus, it may be subdivided further once more sequence information becomes available.

It is of interest that the nucleotide sequence identity of the coat protein gene between the proposed three subgroups of
PSV (about 76\%) was similar to that observed between the two CMV subgroups (18). Compared with CMV, fewer sequences of different strains of PSV have been characterized. However, from these few sequences, the variation between the PSV strains was much greater than that observed between the CMV strains within each subgroup. Further, the degree of variation observed between the deduced amino acid sequences of the PSV strains overlapped that observed between the amino acid sequences of the PSV and TAV strains. This suggests that, while TAV and PSV form different clades (Fig. 2), they probably had a common ancestor, and a continuum of sequences may exist between what is currently considered to be PSV and TAV.

PSV-S and PSV-Mi showed high sequence identity at both the nucleotide and the amino acid levels, but showed different disease severity on peanut. This suggests that neither the coat protein region of the genome nor the coat protein itself is responsible for the differences in symptom severity observed between these two strains.

Phylogenetic analysis showed that the PSV strains included in this study are not related by geographic origin or by symptoms. However, it does appear that they all have a common ancestor, so that the ability of the progenitor virus to infect peanut has probably arisen only once.

Surprisingly, nucleotide sequence alignments of PSV RNA3 revealed that the published PSV-ER coat protein gene sequence appeared to have a single nucleotide deletion 20 nucleotides upstream of the stop codon. The predicted PSV-ER sequence was completely different from all the other strains in the last 19 nucleotides of this gene. However, when a space was inserted in this position, the PSV-ER sequence was then recognizably that of PSV. Thus, this apparent deletion would cause a frame shift that would give rise to an amino acid sequence different in this region from the other PSV strains. It would also be 8 to 11 amino acids longer, or 226 amino acids (8), since the next in-frame stop codon would be further downstream than the one reported for other PSV coat protein sequences $(8,9,17)$. This may have been an artifact of sequencing, or it may be an interesting biological variant and could be clarified by comparative SDS-PAGE analysis of the purified coat protein from PSV-ER and other strains.

\section{ACKNOWLEDGMENTS}

We thank Karen Thomson for assistance with viral RNA extraction, bacterial colony PCR, and sequencing, and Said Ghabrial for providing the sequence of PSV-W RNA3. We also thank Chen Jinxiang and Luo Lixia for technical assistance. This work was supported by Australian Centre for International Agricultural Research, project 9439, and the China National Foundation for Science and International Foundation for Science.

\section{LITERATURE CITED}

1. Ahmed, A. H. 1985. Identification of peanut stunt virus in the Sudan. Plant Dis. 69:173174.

2. Beczner, L., and Devergne, J. C. 1979. Characterization of a new peanut stunt virus strain isolated from Trifolium pratense L. in Hungary. 1. Symptomatological and serological properties. Acta Phytopathol. Acad. Sci. Hung. 14:247-267.

3. Dayhoff, M. O., Barker, W. C., and Hunt, L. T. 1983. Establishing homologies in protein sequences. Methods Enzymol. 91:524-549.

4. Diaz-Ruiz, J. R., and Kaper, J. M. 1983 Nucleotide sequence relationship among thirty peanut stunt virus isolates determined by competition hybridization. Arch. Virol. 75:277-281.

5. Felsenstein, J. 1985. Confidence limits on phylogenies: An approach using the bootstrap. Evolution 39:783-791.

6. Felsenstein, J. 1989. PHYLIP-phylogeny inference package. Version 3.2. Cladistics 5:164-166.

7. Francki, R. I. B., Mossop, D. W., and Hatta, T 1979. Cucumber mosaic virus. CMI/AAB Descriptions of Plant Viruses, No. 213. Commonw. Mycol. Inst./Assoc. Appl. Biol., Kew, Eng.

8. Hu, C. C., Aboul-Ata, A. E., Naidu, R. A., and Ghabrial, S. A. 1997. Evidence for the occurrence of two distinct subgroups of peanut stunt cucumovirus strains: Molecular characterization of RNA3. J. Gen. Virol. 78:929-939.

9. Karasawa, A., Nakaho, K., Kakutani, T., Minobe, Y., and Ehara, Y. 1991. Nucleotide sequence of RNA3 of peanut stunt cucumovirus. Virology 185:464-467.

10. Karasawa, A., Nakaho, K., Kakutani, T., Minobe, Y., and Ehara, Y. 1992. Nucleotide sequence analyses of peanut stunt cucumovirus RNA1 and 2. J. Gen. Virol. 73:701-707.

11. Kimura, M. 1980. A simple model for estimating evolutionary rates of base substitutions through comparative studies of nucleotide sequences. J. Mol. Evol. 16:111-120.

12. Matthews, R. E. F. 1992. Criteria for the recognition of strains. Pages 482-503 in: Plant Virology. 3rd ed. Academic Press, San Diego.

13. Messing, I. 1983. Methods Enzymol. 101. R Wu, L. Grossman, and K. Moldave, eds. Academic Press, New York. pp. 20-78.

14. Mink, G. I. 1972. Peanut stunt virus CMI/AAB Descriptions of Plant Viruses, No. 92. Commonw. Mycol. Inst./Assoc. Appl. Biol., Kew, Eng.

15. Mink, G. I., Silbernagel, M. J., and Saksena, K. N. 1969. Host range, purification, and properties of the western strain of peanut stunt virus. Phytopathology 59:1625-1631.

16. Naidu, R. A., Collins, G. B., and Ghabrial, S A. 1991. Nucleotide sequence analysis of a cDNA clone encoding the coat protein gene of peanut stunt virus. Plant Mol. Biol. 17:175177.

17. Naidu, R. A., Hu, C.-C., Pennington, R. E., and Ghabrial, S. A. 1995. Differentiation of eastern and western strains of peanut stunt cucumovirus based on satellite RNA support and nucleotide sequence homology. Phytopathology 85:502-507.

18. Palukaitis, P., Roossinck, M. J., Dietzgen, R. G., and Francki, R. I. B. 1992. Cucumber mosaic virus. Adv. Virus Res. 41:281-348.

19. Rybicki, E. P. 1995. The Bromoviridae. In: Virus Taxonomy. Sixth Report of the International Committee on Taxonomy of Viruses. F A. Murphy et al., eds. Arch. Virology, Suppl. 10:450-457.

20. Sanger, F., Nicklen, S., and Coulson, A. R. 1977. DNA sequencing with chain-terminating inhibitors. Proc. Nat. Acad. Sci., USA 
74:5463-5467

21. Tompson, J. D., Higgins, D. G., and Gibson, T. J. 1994. Clustal W: Improving the sensitivity of progressive multiple sequence alignment through sequence weighting, position-specific gap penalties and weight matrix choice. Nucl. Acids Res. 22:46734680.

22. Xu, Z., Barnett, O. W., and Gibson, P. B.
1986. Characterization of peanut stunt virus strains by host reactions, serology, and RNA patterns. Phytopathology 76:390-395.

23. Xu, Z., Chen, K., Chen, G., and Cao, G. 1994. Black locust, primary source of peanut stunt virus (PSV) for the PSV epidemics on peanut. Acta Phytopathol. Sinica 24:305-309.

24. Xu, Z., and Zhang, Z. 1985. Peanut stunt virus (PSV) mild strain, a new strain of PSV.
Oil Crops China 2:68-72.

25. Xu, Z., and Zhang, Z. 1988. Distribution of peanut virus diseases and detection of viruses by serology in China. Oil Crops China 2:5661

26. Zhang, Z., Xu, Z., Chen, K., Chen, J., and Yang, S. 1990. A preliminary study on an isolate of peanut stunt virus from black locust tree. Chinese J. Virol. 6:380-382. 